\title{
ESTIMATION OF STATURE FROM FOOT OUTLINE IN ADULT MALAYSIAN MALAYALEE ETHNICS FOR FORENSIC INVESTIGATION
}

\author{
T. Nataraja Moorthy ${ }^{1}$ \& Rasvini Asogan ${ }^{2}$ \\ ${ }^{1}$ Associate Professor of Forensic Sciences, Management and Science \\ University, Shah Alam, Selangor, Malaysia. \\ ${ }^{2}$ Forensic Science Program, Management and Science University, \\ Shah Alam, Selangr
}

\begin{abstract}
Identification is a key component in any forensic investigation. Estimation of stature is an identifying characteristics to solve the crime. Foot impression is known to be a valuable scientific evidence encountered in the scenes of crime. Examination of footprint helps in estimation of stature of an individual since there is a strong relationship exists between foot impression and stature. There are people who still have the habit of walking barefoot in Asian countries like Malaysia, Sri Lanka, India, Thailand and Indonesia. The hard surfaces produce two-dimensional footprints while foot outline provides the size parameters of the fleshed bare foot and also represents the boundaries of the foot's impression in soft soil, mud, or any other substances that produces a three-dimensional foot impression. It is shown that very limited studies were conducted on stature estimation from foot outline measurements. It is important to note that racial and cultural aspects of foot morphology must be considered while conducting the foot impression study. Researchers have cautioned that regression equations derived to estimate stature from foot impression for a particular population is erroneous to apply for other populations. Thus the present investigation is aimed to derive linear regression equations to estimate stature from foot outlines of Malaysian Malayalee ethnics.
\end{abstract}

Key words: Forensic Science, Forensic anthropology, Stature estimation, Foot outline, Malaysian Malayalee ethnics

Corresponding author:

natrajamoorthy@rediffmail.com

\section{INTRODUCTION}

The anthropometry-based Bertillon system was invented by French anthropologist Alphonse Bertillon for the purpose of human identification ${ }^{1}$. Stature can be estimated using various body parts since there is a strong relationship exists between each part of the body and whole body ${ }^{2-6}$. Nothing exemplifies this truth more than the relationship that various parts of the body have to the stature of an individual ${ }^{7}$. In this way, an individual's foot impression may represent his or her identity. There are people who still have the habit of walking barefoot in Asian countries like Malaysia, Sri Lanka, India, Thailand and Indonesia ${ }^{8}$. Foot impressions are still found at crime scenes, since offenders often tend to remove their footwear either to avoid noise or to gain better grip in climbing walls, etc., while entering or exiting9. The foot impressions with characteristic features can provide valuable information even from partial foot impressions (2D \& 3D) during crime scene investigation ${ }^{10}$. Stature can be estimated from anthropometric measurements of foot ${ }^{11-16}$, footprint ${ }^{17-21}$ and foot outline ${ }^{22-25}$ 
because correlation exists between stature and foot/footprint/foot outline. The hard surfaces produce two-dimensional (2D) footprints while foot outline provides the size parameters of the fleshed bare foot and also represents the boundaries of the foot's impression in soft soil, mud, or any other substances that produces a three-dimensional (3D) footprint impression ${ }^{26}$. Earlier foot/footprint/foot outline studies have been conducted on mixed populations. Researchers have cautioned that regression equations derived to estimate stature from foot impression for a particular population is erroneous to apply for other populations ${ }^{9-10}$. Hence, the present study is aimed to derive population specific regression equations to estimate stature from foot outline measurements of Malaysian Malayalee ethnics.

\section{MATERIALS AND METHODS}

\section{Research location}

The research location is Peninsular Malaysia, wherein most of the Malayalee are living. The Malaysian Malayalees have ancestral origins in the modern day state of Kerala, on south west coast of India with their mother tongue Malayalam. Although there are more than thirty-five million Malayalam language speakers in India, there are about 135,000 Malayalees are living in Malaysia. They have an association in Malaysia named as "All Malaysia Malaylee Association" or abbreviated as AMMA.

\section{Sample collection}

Based on the population, the study involved 110 adult Malaysian Malayalees (50 males, 60 females) of age ranged from 18 to 56 years. Subjects with any apparent foot-related disease, orthopaedic deformity, injury and age below 18 years were excluded from the study. Informed consent and ethical approval were obtained before sample collection. Stature measurements and foot outlines were recorded following the procedure adopted by Nataraja Moorthy ${ }^{23-25}$. Stature of each subject was measured using a portable body meter measuring device (SECA model 206).

The height of the subjects was measured at a fixed time in the evening because of diurnal variation in stature. After cleaning the feet of the subjects, the left foot was requested to place on an A4 size white paper and the foot outline was drawn with a sharp-pointed pencil and the anatomical landmarks of the foot, namely mid-rear heel point (pternion,P) in the base line and most anterior points of all toes (LT1-LT5) were marked (Figure 1). The procedure was repeated for the right foot and for other subjects. All foot outline samples and information relating to participants were coded with sample ID for anonymity.

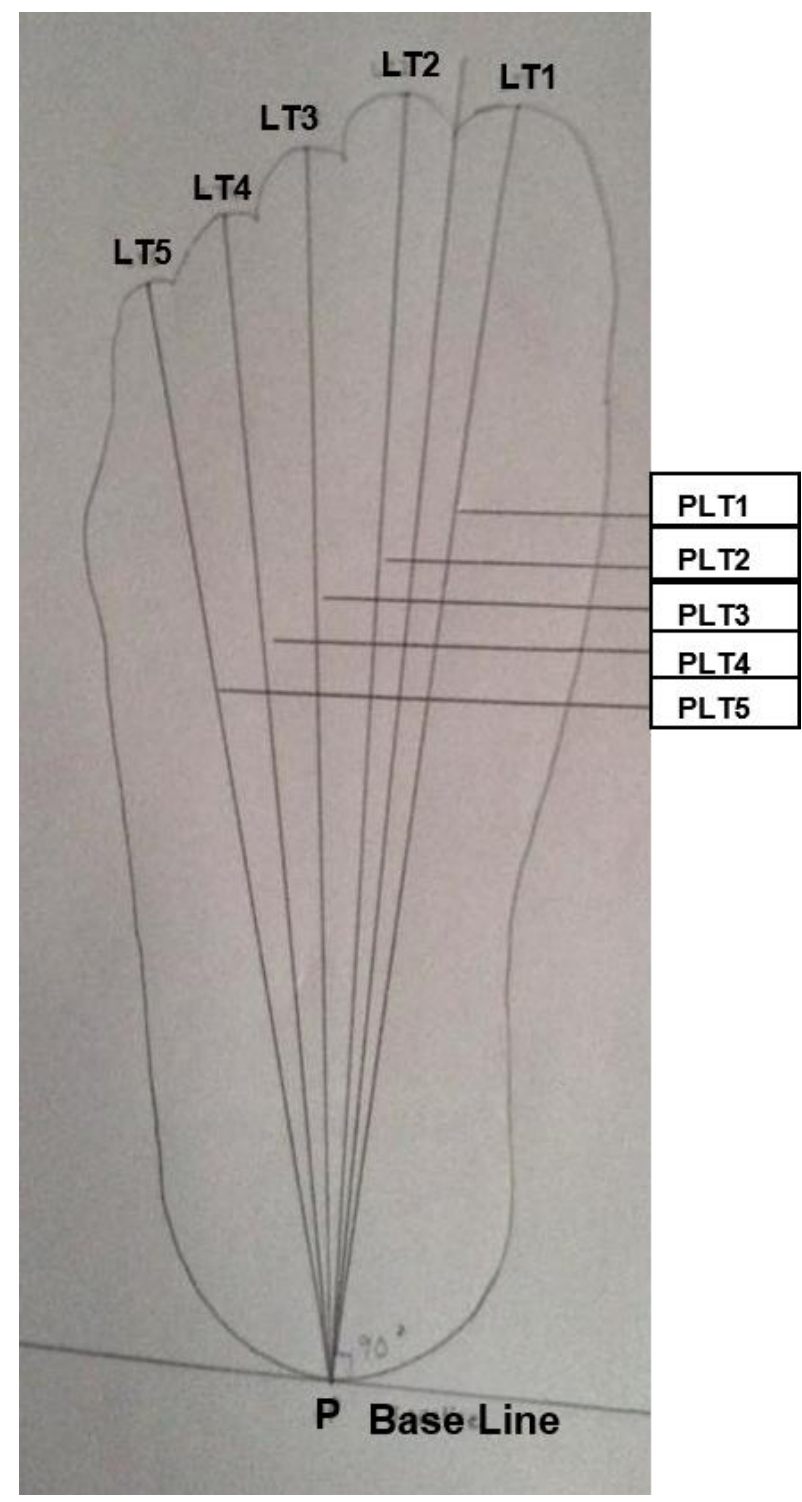

Figure 1: Landmarks and diagonal length measurements on left foot outline 


\section{Statistical analysis}

The data were analyzed using SPSS software version 21. Bilateral asymmetry was calculated for each of the foot outline measurements and tested for significance using one sample t-test. Pearson's correlation coefficients $(\mathrm{R})$ between various feet outline lengths and stature were obtained. The linear regression analysis method was employed to derive regression equations for stature estimation from various foot outline lengths since stature estimation from foot outline length is more accurate and reliable with regression analysis ${ }^{27}$. The standard error of estimation (SEE) was calculated to analyze the deviation of the estimated stature from the actual stature for foot outline measurements.

\section{RESULTS}

All foot outline measurements exhibit statistically positive significant correlation with stature. Table- 1 shows the descriptive statistics of stature measurements in males, females and pooled sample. In males, the stature ranges from 154.0 to $182.0 \mathrm{~cm}$ (mean $167.9 \mathrm{~cm}$ ) and in females, it ranges from 139.0 to $167.0 \mathrm{~cm}$ (mean $153.1 \mathrm{~cm}$ ). In pooled sample, the stature ranges from 139.0 to $182.0 \mathrm{~cm}$ (mean 159.7). The results showed that mean stature is found to be significantly higher in males than females.

Table 1: Descriptive statistics of stature in males, females and pooled sample of adult Malaysian Malayalees (in centimeters).

\begin{tabular}{|l|c|c|c|c|c|}
\hline & Min & Max & Mean & RD & SD \\
\hline Male $(\mathrm{N}=50)$ & 154.00 & 182.0 & 167.9 & 28.0 & 7.2 \\
\hline Female $(\mathrm{N}=60)$ & 139.0 & 167.0 & 153.1 & 28.0 & 6.9 \\
\hline Pooled sample $(\mathrm{N}=110)$ & 139.0 & 182.0 & 159.7 & 43.0 & 10.2 \\
\hline
\end{tabular}

SD: standard deviation; RD: range difference; Min: minimum; Max: maximum; Table 2 to 4 present the descriptive statistics of various foot outline lengths i.e. diagonal length between the rear heel end $(\mathrm{P})$ and anterior points of each toe in both left (LT1-LT5) and right (RT1-RT5) of males, females and pooled sample. All the foot outline length measurements in males are found to be larger than females both in left and right feet.

Table 2: Descriptive statistics of foot outline length measurements in males in adult Malaysian Malayalees (in centimeters). $N=50$

\begin{tabular}{|c|c|c|c|c|c|}
\hline Variables & Min & Max & Mean & RD & SD \\
\hline PLT1 & 22.1 & 28.5 & 25.80 & 6.4 & 1.4 \\
\hline PLT2 & 21.6 & 27.8 & 25.27 & 6.2 & 1.4 \\
\hline PLT3 & 21.0 & 26.8 & 24.47 & 5.8 & 1.3 \\
\hline PLT4 & 20.0 & 25.1 & 23.18 & 5.1 & 1.2 \\
\hline PLT5 & 18.6 & 23.8 & 21.51 & 5.2 & 1.2 \\
\hline PRT1 & 22.1 & 28.1 & 25.54 & 6.0 & 1.4 \\
\hline PRT2 & 21.7 & 27.6 & 25.16 & 5.9 & 1.2 \\
\hline PRT3 & 21.2 & 26.8 & 24.46 & 5.6 & 1.2 \\
\hline PRT4 & 20.5 & 25.0 & 23.18 & 4.5 & 1.1 \\
\hline PRT5 & 19.1 & 23.8 & 21.59 & 4.7 & 1.0 \\
\hline
\end{tabular}


Min: minimum; Max: maximum; PLT1 to PLT5: left lengths from anterior part of toes outlines LT1- LT5 to outline mid-rear outline heel point P; PRT1 to PRT5: right lengths from anterior part of toes outline RT1-RT5 to mid-rear outline heel point P; RD: range difference; SD: standard deviation; $\mathrm{N}$ : number of samples.

Table 3: Descriptive statistics of foot outline length measurements in females in adult Malaysian Malayalees (in centimeters). $N=60$

\begin{tabular}{|c|c|c|c|c|c|}
\hline Variables & Min & Max & Mean & RD & SD \\
\hline PLT1 & 20.5 & 26.0 & 23.55 & 5.5 & 1.3 \\
\hline PLT2 & 20.4 & 25.4 & 23.02 & 5.0 & 1.3 \\
\hline PLT3 & 19.7 & 24.7 & 22.17 & 5.0 & 1.3 \\
\hline PLT4 & 18.3 & 23.7 & 20.99 & 5.4 & 1.2 \\
\hline PLT5 & 17.4 & 22.0 & 19.54 & 4.6 & 1.1 \\
\hline PRT1 & 21.1 & 25.5 & 23.47 & 4.4 & 1.2 \\
\hline PRT2 & 20.8 & 25.2 & 23.05 & 4.4 & 1.1 \\
\hline PRT3 & 20.1 & 24.7 & 22.30 & 4.6 & 1.1 \\
\hline PRT4 & 19.2 & 23.6 & 21.17 & 4.4 & 1.1 \\
\hline PRT5 & 18.3 & 21.7 & 19.73 & 3.4 & 0.9 \\
\hline
\end{tabular}

Min: minimum; Max: maximum; PLT1 to PLT5: left lengths from anterior part of toes outlines LT1- LT5 to outline mid-rear outline heel point P; PRT1 to PRT5: right lengths from anterior part of toes outline RT1-RT5 to mid-rear outline heel point P; RD: range difference; SD: standard deviation; $\mathrm{N}$ : number of samples.

Table 4: Descriptive statistics of foot outline length measurements in pooled sample in adult Malaysian Malayalees (in centimeters). $N=110$

\begin{tabular}{|c|c|c|c|c|c|}
\hline Variables & Min & Max & Mean & RD & SD \\
\hline PLT1 & 20.5 & 28.5 & 24.57 & 8.0 & 1.8 \\
\hline PLT2 & 20.4 & 27.8 & 24.04 & 7.4 & 1.7 \\
\hline PLT3 & 19.7 & 26.8 & 23.22 & 7.1 & 1.7 \\
\hline PLT4 & 18.3 & 25.1 & 21.99 & 6.8 & 1.6 \\
\hline PLT5 & 17.4 & 23.8 & 20.44 & 6.4 & 1.5 \\
\hline PRT1 & 21.1 & 28.1 & 24.41 & 7.0 & 1.6 \\
\hline PRT2 & 20.8 & 27.6 & 24.01 & 6.8 & 1.6 \\
\hline PRT3 & 20.1 & 26.8 & 23.29 & 6.7 & 1.6 \\
\hline PRT4 & 19.2 & 25.0 & 22.08 & 5.8 & 1.5 \\
\hline PRT5 & 18.3 & 23.8 & 20.57 & 5.5 & 1.4 \\
\hline
\end{tabular}

Min: minimum; Max: maximum; PLT1 to PLT5: left lengths from anterior part of toes outlines LT1- LT5 to outline mid-rear outline heel point P; PRT1 to PRT5: right lengths from anterior part of toes outline RT1-RT5 to mid-rear outline heel point P; RD: range difference; SD: standard deviation; $\mathrm{N}$ : number of samples.

A salient feature observed in the foot outline lengths is that the first toe-heel foot outline length in both left and right are found to be the longest in males and females in both genders. The left foot outline lengths are found to be larger than the right in both males and females showing the existence of bilateral asymmetry. 
Table 5-7 depict the linear regression equations for stature estimation in adult males, females and the pooled sample through various foot outline length measurements and ANOVA.

Table 5: Linear regression equations for stature estimation through various foot outline length measurements and ANOVA in adult male Malaysian Malayalees (in centimeters). $N=50$

\begin{tabular}{|l|l|c|c|c|c|c|}
\hline $\begin{array}{c}\text { Varia- } \\
\text { bles }\end{array}$ & Regression Equations & SEE & $R$ & $R^{2}$ & $\begin{array}{c}\text { Coefficient } \\
\text { of t-test }\end{array}$ & ANOVA \\
\hline PLT1 & $56.731+4.310$ PLT1 & 3.792 & 0.86 & 0.732 & 11.436 & $130.791(1,48) ; p<0.001$ \\
\hline PLT2 & $60.116+4.267$ PLT2 & 4.362 & 0.80 & 0.645 & 9.334 & $87.129(1,48) ; p<0.001$ \\
\hline PLT3 & $59.598+4.427$ PLT3 & 4.495 & 0.79 & 0.623 & 8.901 & $79.232(1,48) ; p<0.001$ \\
\hline PLT4 & $60.249+4.647$ PLT4 & 4.589 & 0.78 & 0.607 & 8.607 & $74.081(1,48) ; p<0.001$ \\
\hline PLT5 & $66.924+4.696$ PLT5 & 4.860 & 0.75 & 0.559 & 7.801 & $60.853(1,48) ; p<0.001$ \\
\hline PRT1 & $59.707+4.237$ PRT1 & 4.404 & 0.80 & 0.638 & 9.195 & $84.556(1,48) ; p<0.001$ \\
\hline PRT2 & $57.332+4.396$ PRT2 & 4.783 & 0.76 & 0.573 & 8.025 & $64.394(1,48) ; p<0.001$ \\
\hline PRT3 & $58.276+4.483$ PRT3 & 4.819 & 0.75 & 0.566 & 7.917 & $62.683(1,48) ; p<0.001$ \\
\hline PRT4 & $59.513+4.678$ PRT4 & 5.011 & 0.73 & 0.531 & 7.375 & $54.393(1,48) ; p<0.001$ \\
\hline PRT5 & $59.818+5.008$ PRT5 & 5.127 & 0.71 & 0.509 & 7.056 & $49.783(1,48) ; p<0.001$ \\
\hline
\end{tabular}

PLT1 to PLT5: left lengths from anterior part of toes outline LT1- LT5 to outline mid-rear heel point P; PRT1 to PRT5: right lengths from anterior part of toes outline RT1-RT5 to outline mid-rear heel point P; SEE: standard error of estimate; R: Correlation coefficient; $\mathrm{R}^{2}$ : coefficient of determination. p-value $<0.001$ is significant

Table 6: Linear regression equations for stature estimation through various foot outline length measurements and ANOVA in adult female Malaysian Malayalees (in centimeters). $N=60$

\begin{tabular}{|c|c|c|c|c|c|c|}
\hline $\begin{array}{c}\text { Varia- } \\
\text { bles }\end{array}$ & Regression Equations & SEE & $R$ & $R^{2}$ & $\begin{array}{c}\text { Coefficient } \\
\text { of t-test }\end{array}$ & ANOVA \\
\hline PLT1 & $68.600+3.590$ PLT1 & 5.053 & 0.68 & 0.468 & 7.140 & $50.980(1,58) ; p<0.001$ \\
\hline PLT2 & $68.827+3.662$ PLT2 & 5.103 & 0.68 & 0.457 & 6.992 & $48.885(1,58) ; p<0.001$ \\
\hline PLT3 & $77.127+3.428$ PLT3 & 5.228 & 0.66 & 0.430 & 6.618 & $43.804(1,58) ; p<0.001$ \\
\hline PLT4 & $74.370+3.752$ PLT4 & 5.105 & 0.68 & 0.457 & 6.984 & $48.780(1,58) ; p<0.001$ \\
\hline PLT5 & $63.983+4.562$ PLT5 & 4.882 & 0.71 & 0.503 & 7.666 & $58.765(1,58) ; p<0.001$ \\
\hline PRT1 & $60.438+3.950$ PRT1 & 5.178 & 0.66 & 0.441 & 6.766 & $45.776(1,58) ; p<0.001$ \\
\hline PRT2 & $57.231+4.161$ PRT2 & 4.992 & 0.69 & 0.481 & 7.327 & $53.691(1,58) ; p<0.001$ \\
\hline PRT3 & $61.899+4.091$ PRT3 & 5.111 & 0.68 & 0.456 & 6.966 & $48.526(1,58) ; p<0.001$ \\
\hline PRT4 & $60.150+4.392$ PRT4 & 4.929 & 0.70 & 0.494 & 7.521 & $56.567(1,58) ; p<0.001$ \\
\hline PRT5 & $51.776+5.139 P R T 5$ & 4.952 & 0.70 & 0.489 & 7.449 & $55.489(1,58) ; p<0.001$ \\
\hline
\end{tabular}

PLT1 to PLT5: left lengths from anterior part of toes outline LT1- LT5 to outline mid-rear heel point P; PRT1 to PRT5: right lengths from anterior part of toes outline RT1-RT5 to outline mid-rear heel point P; SEE: standard error of estimate; R: Correlation coefficient; $\mathrm{R}^{2}$ : coefficient of determination. p-value $<0.001$ is significant 
Table 7: Linear regression equations for stature estimation through various foot outline lengths measurements and ANOVA in pooled samples in Malaysian Malayalees (in centimeters). $N=110$

\begin{tabular}{|c|c|c|c|c|c|c|}
\hline $\begin{array}{c}\text { Varia- } \\
\text { bles }\end{array}$ & Regression Equations & SEE & $R$ & $R^{2}$ & $\begin{array}{c}\text { Coefficient } \\
\text { of t-test }\end{array}$ & ANOVA \\
\hline PLT1 & 36.625 PLT1 + 5.016 & 5.057 & 0.87 & 0.756 & 18.307 & $335.157(1,108) ; p<0.001$ \\
\hline PLT2 & 37.858 PLT2 + 5.074 & 5.256 & 0.86 & 0.737 & 17.386 & $302.259(1,108) ; p<0.001$ \\
\hline PLT3 & 43.716 PLT3 + 5.002 & 5.387 & 0.85 & 0.723 & 16.810 & $282.565(1,108) ; p<0.001$ \\
\hline PLT4 & $42.909 P L T 4+5.320$ & 5.319 & 0.86 & 0.730 & 17.104 & $292.554(1,108) ; p<0.001$ \\
\hline PLT5 & 39.071 PLT5 + 5.911 & 5.277 & 0.86 & 0.735 & 17.292 & $299.012(1,108) ; p<0.001$ \\
\hline PRT1 & 29.483 PRT1 + 5.341 & 5.380 & 0.85 & 0.724 & 16.840 & $283.602(1,108) ; p<0.001$ \\
\hline PRT2 & 28.221 PRT2 + 5.483 & 5.313 & 0.86 & 0.731 & 17.131 & $293.471(1,108) ; p<0.001$ \\
\hline PRT3 & 32.526 PRT3 + 5,469 & 5.346 & 0.85 & 0.728 & 16.986 & $288.517(1,108) ; p<0.001$ \\
\hline PRT4 & 31.532 PRT4 + 5.811 & 5.363 & 0.85 & 0.726 & 16.913 & $286.050 \mathrm{~V}(1,108) ; p<0.001$ \\
\hline PRT5 & 27.382 PRT5 + 6.439 & 5.349 & 0.85 & 0.727 & 16.974 & $288.117(1,108) ; p<0.001$ \\
\hline
\end{tabular}

PLT1 to PLT5: left lengths from anterior part of toes outline LT1- LT5 to outline mid-rear heel point P; PRT1 to PRT5: right lengths from anterior part of toes outline RT1-RT5 to outline mid-rear heel point P; SEE: standard error of estimate; R: Correlation coefficient; $\mathrm{R}^{2}$ : coefficient of determination.

$\mathrm{p}$-value $<0.001$ is significant

Correlation coefficient $(\mathrm{R})$ values are found to be higher in the pooled sample $(0.85-0.87)$ when compared with males $(0.71-0.86)$ and females (0.66-0.71) separately. The coefficient of determination $\left(\mathrm{R}^{2}\right)$, the predictive accuracy, is found to be higher in the pooled sample $(0.723$ 0.756) when compared with males (0.509-0.732) and females (0.430-0.494) and all measurements are found to be positive and statistically significant $(<0.001)$ for stature estimation.
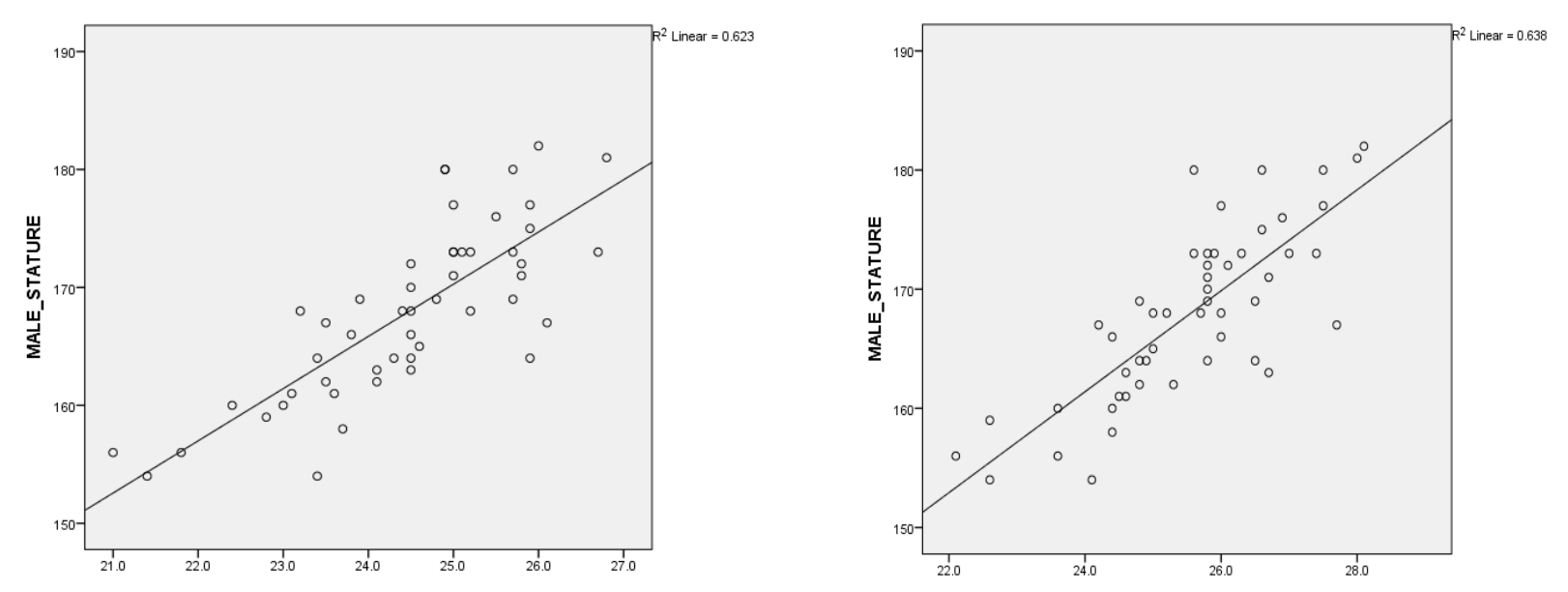

Figure 2: Illustrative examples of scatter graphs showing the relationship between foot outline lengths (left and right) and stature in adult male Malaysian Malayalees. 

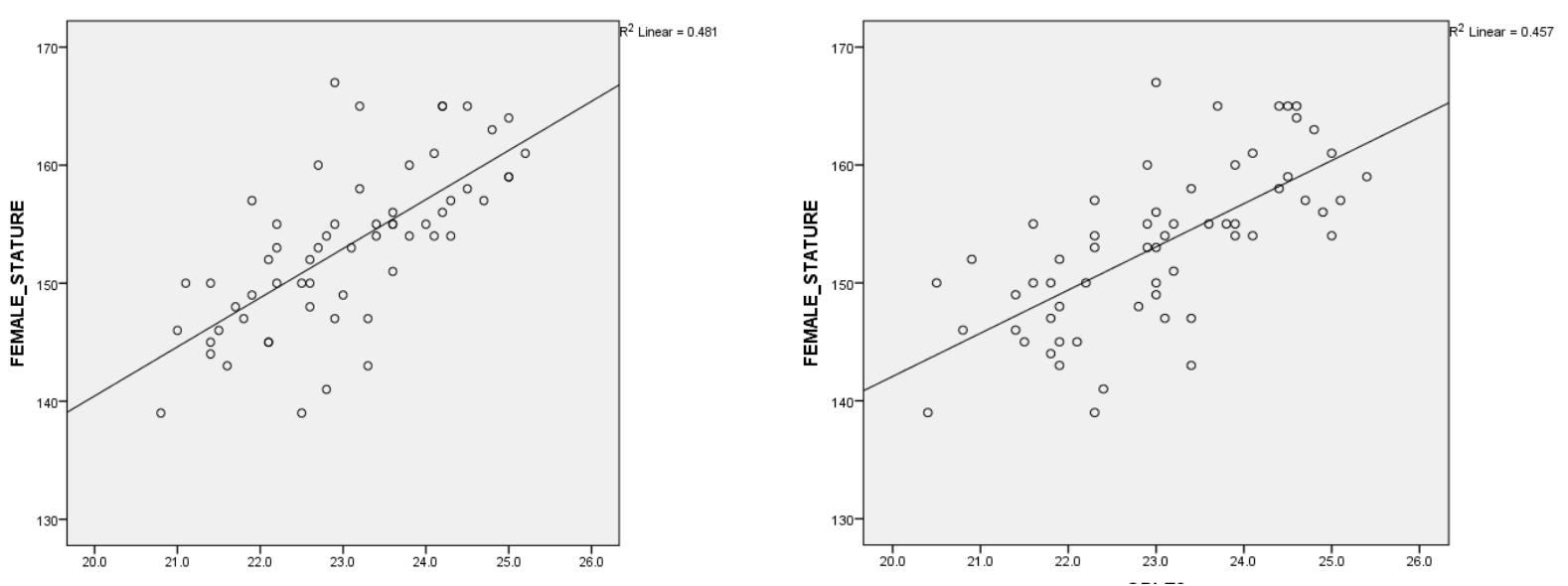

Figure 3: Illustrative examples of scatter graphs showing the relationship between foot outline lengths (left and right) and stature in adult female Malaysian Malayalees.
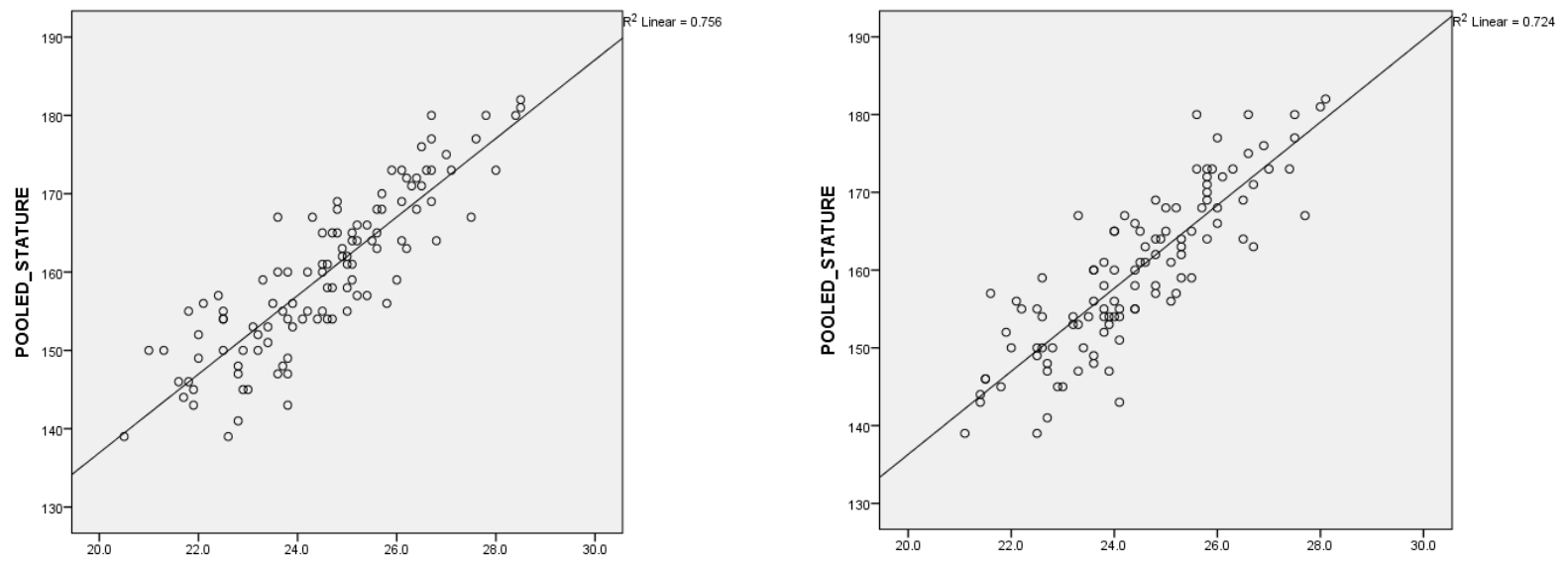

Figure 4: Illustrative examples of scatter graphs showing the relationship between foot outline lengths (left and right) and stature in pooled samples of Malaysian Malayalees.

A few illustrative examples of graphs with fitted lines for foot outline and stature in males (Figure 2), females (Figure 3) and the pooled sample (Figure 4) are presented. All graphs show positive correlaton between staure and foot outline length measurements.

\section{DISCUSSION}

Stature is found to be larger in males than females, showing the existance of a statistically significant gender difference in Malaysian Malayalees. This may be attributed general male-female differences and natural size in both sexes. This finding is in accordance with the previous studies ${ }^{22-28}$. The foot outline provided the size parameters of the fleshed bare foot and also represents the boundaries of the foot's impression in soft soil surfaces that produces a 3D footprint impression. The investigation revealed that the left foot outline measurements are found to be larger in both sexes and hence the existence of left-sided asymmetry. Similar observations were noted in Malaysian Malays $^{9}$, male Gujjars of North India ${ }^{10}$, male Egyptian $^{17}$, Indian ${ }^{29}$ and male Jat Sikh in North Indian ${ }^{30}$. Researchers ${ }^{31}$ suggested that in majority of both left and right handed persons, the left foot is more used than the right. 
The age of the subjects is above 18 years and considered appropriate since average length of the adult's foot is attained by the age of 16 years in male and 14 years in females ${ }^{32}$. The researchers concluded that to estimate stature, irrespective of ethnics, toe-to-heel length measurements are more reliable and accurate than from any other measurements such as breadth measurements etc. ${ }^{9-10,21-22}$. The result of the study indicated that the correlation coefficient (R) between stature and foot outline length measurements is higher in pooled sample compared to male and female individually. Hence the regression equations derived for pooled samples can be used to estimate stature since the sex of the 3D foot impression is unknown in real crime scenes. The standard error of estimate (SEE) is a measure of accuracy of predictions. Researchers shown that regression equations can be derived for stature estimation using foot and hand measurements with a great accuracy in both males and females show high reliability and accuracy with low SEE. The SEE values are found to be low in the present study.

\section{CONCLUSION}

The result of this research provided linear regression equations for stature estimation from foot outline (3D foot impression) anthropometry in Malaysian Malayalee ethnics. The findings of the study will be applicable to complete and even partial foot impressions found in soft soil or mud. The research shows that the regression equation without gender indicators perform significantly better that do models with sex indications, as in real crime scenarios.

\section{CONFLICT OF INTEREST}

The authors have no conflict of interest to declare.

\section{ACKNOWLEDGMENT}

The authors are thankful to all participants who took part in this strenuous study. Authors are grateful to Management and Science University for encouraging research and its publication in international journals.

\section{REFERENCES}

1. Kennedy KAR. Forensic anthropology in the USA. In: Siegel J, Knupfer G, Saukko P, editors. Encycolopedia of forensic sciences. London (SanDiego): Academic Press; 2000. pp. 1059-1064.

2. Ozaslan A, Iscan MY, Ozaslan I, Tugcu H, Koc S. Estimation of stature from body parts. Forensic Science International. 2003; 132 (1): 40-45.

3. Zverev YP. Relationship between arm span and stature in Malawian adults. Annals of Human Biology. 2003; 30 (6):739-743.

4. Sanli SG, Kizilkanat ED, Boyan N, Ozsahin ET, Bozkir MG, Soakes R, Erol H, Oguz O. Stature estimation based on hand length and foot length. Clinical Anatomy. 2005; 18 (8): 589-596.

5. Mahakkanukrauh $P, \quad$ Khanpetch $P$, Prasitwattanseree S, Vichairat K, Troy Case D. Stature estimation from long bone length in a Thai population. Forensic Science International. 2011; 210: 279 e1-7.

6. Pelin C, Duyar I, Kayahan EM, Zagyapan R, Agildere AM, Erar A. Body height estimation based on dimensions of sacral and coccygeal vertebrae. Journal of Forensic Science. 2005; 50 (2): 294-297.

7. Philip TA. Formulae for establishing stature from foot size by regression method. Journal of Indian Academy of Forensic Medicine. 1990; 12:57-62.

8. Hairunnisa MAK and Nataraja Moorthy T. Stature estimation from the anthropometric measurements of foot outline in adult indigenous Melanau ethnics of east Malaysia by regression analysis. Sri Lanka Journal of Forensic Medicine, Science \& Law. 2013;4 (2):27-35. 
9. Nataraja Moorthy T, Mazidah K, Hadzri M, Jayaprakash PT. Estimation of stature based on foot length of Malays in Malaysia. Australian Journal of Forensic Sciences 2011;43:13-26.

10. Krishan K. Individualizing characteristics of footprints in Gujjars of north India-forensic aspects. Forensic Science International 2007; 169:137-144.

11. Ilayperuma I, Nanayakkara BG, Palahepitiya $\mathrm{KN}$. A model for reconstruction of personal stature based on the measurements of foot length. Galle Medical Journal 2008;13(1): 6-9

12. Petra U, Radoslav B, Sona M. Stature estimation from various foot dimensions among Slovak population. Journal of Forensic Sciences 2013; 58(2): 448-451.

13. Mansur DI, Haque MK,Sharma K, Karki RK, Khanal K,Karna R. Estimation of Stature from foot length in adult Nepalese population and its clinical relevance. Kathmandu University Medical Journal 2012; 37(1):16-9.

14. Sonali K,Ashias A. Estimation of stature from the measurement of foot length, hand length and head length in Maharashtra region. Indian Journal of Basic \& Applied Medical Research 2012; 1(2): 77-85.

15. Salina H, Mamat S, Che R, Ibrahim, Mohamad A. Regression analysis for stature estimation from foot anthropometry in Malaysian Chinese. Australian Journal of Forensic Sciences 2012; 44 (4): 333-341.

16. Pradeep KP, Abhilasha D. Study of correlation between human height and foot length in residents of Mumbai. International Journal of biological and medical research 2012; 3(3): 2072 -2075.

17. Irene Atef Fawzy,1 M.D. and Nashwa Nabil Kamal,2 M.D. Stature and Body Weight Estimation from various footprint measurements among Egyptian population. Journal of Forensic Sciences 2010; 55(4): 884-888

18. Reel S, Rouse S, Vernon W, Doherty D. Estimation of stature from static and dynamic footprints. Forensic Science International 2012; 219: 283.e1-283.e5.
19. Naomi H, Ambika F, Nur-Intaniah I, Daniel F, Tytul A. Estimation of stature using anthropometry of feet and footprints in a Western Australian population. Journal of Forensic and Legal Medicine 2013; 20(5): 435-441.

20. Nataraja Moorthy T, Nurul A, Hairun Nisa M. Stature estimation based on footprint measurements of Malays in Peninsula Malaysia by regression analysis. International Journal of biomedical and advance research 2013; 4(10):683-689.

21. Nataraja Moorthy $T$, Mustaqqim A, Boominathan R, Raman N. Stature estimation from footprint measurements in Indian Tamils by regression analysis. Egyptian Journal of Forensic Sciences. 2014; 4:7-16.

22. Hairunnisa MAK and Nataraja Moorthy T. Stature estimation from foot outline measurements in adult Bidayuhs of east Malaysia by regression analysis. Indonesian Journal of legal and forensic sciences. 2013;3 (1); 6-10.

23. Hairunnisa MAK and Nataraja Moorthy T. Estimation of stature from foot outline measurements in Ibans of of east Malaysia by regression analysis. International journal of biomedical and advance research. 2013;4 (12); 889-895.

24. Nataraja Moorthy T, Ang YL, Saufee AS and Nik Fakhruddin NH. Estimation of stature from footprint and foot outline measurements in Malaysian Chinese. Australian Journal of Forensic Sciences. 2014;46 (2); 136-159.

25. Robbins LM. Estimating height and weight from size of footprints. Journal of Forensic Sciences 1986; 31:143-52.

26. Krishan K, Kanchan T, Sharma A. Multiplication factor versus regression analysis in stature estimation from hand and foot dimensions. Journal of Forensic and Legal Medicine 2012; 19:211-214.

27. Gulsah Z, Ipek E, Zehra D. Stature and gender estimation using foot measurements. Forensic Science International. 2008;181:54e1-54e5. 
28. Tanuj K, Ritesh G, Rohan M, Ramneet K, Kotian MS, Rakesh K. Stature estimation from foot length using universal regression formula in a north Indian population. Journal of Forensic Science. 2010;55:163-166.

29. Tanuj K, Krishan K, Shyamsundar S, Aparna KR, Sankalp J. Analysis of footprint and its parts for stature estimation in Indian population. The foot. 2012;22:175-180.

30. Jasuja OP, Singh J, Manjari J. Estimation of stature from foot and shoe measurements by multiplication factors: a revised attempt. Forensic Sci Int. 1991;50:203-215.
31. Chhibber SR, Singh I. Asymmetry in muscle weight and one-sided dominance in the human lower limbs. Journal of Anatomy. 1970;106:553-556.

32. Anderson M, Bias M, Green WT. Growth of the normal foot during childhood and adolescence- length of the foot and interrelations of foot, stature and lower extremity as seen in serial records of children between 1-18 years of age. Am J Phys Anthropol. 1956;14:287-308. 